\title{
Static Strength Analysis and Experimental Research of Clinched Joints By Two-strokes Flattening Clinching Method
}

Hao Peng ( $\nabla$ tomoreinnovation@sina.com )

Central South University https://orcid.org/0000-0002-9522-3148

Chao Chen

Central South University

XiaoQiang Ren

Central South University

XiangKun Ran

Central South University

Denglin Qin

Central South University

\section{Research Article}

Keywords: Two-strokes flattening clinching, Static strength analysis, Mechanical properties, Hardening exponent

Posted Date: July 13th, 2021

DOl: https://doi.org/10.21203/rs.3.rs-557639/v1

License: (c) (1) This work is licensed under a Creative Commons Attribution 4.0 International License. Read Full License

Version of Record: A version of this preprint was published at The International Journal of Advanced Manufacturing Technology on January 15th, 2022. See the published version at https://doi.org/10.1007/s00170-021-08438-9. 


\title{
Static strength analysis and experimental research of clinched joints by two-strokes flattening clinching method
}

\author{
Hao Peng ${ }^{1}$, Chao Chen ${ }^{*, 1,2}$, Xiaoqiang Ren ${ }^{1,2}$, Xiangkun Ran ${ }^{1,2}$, Denglin Qin ${ }^{1,2}$ \\ ${ }^{1}$ State Key Laboratory of High Performance Complex Manufacturing, Light Alloy Research Institute, \\ Central South University, Changsha 410083, China \\ ${ }^{2}$ School of Mechanical and Electrical Engineering, Central South University, Changsha 410083, China \\ * Corresponding author: profchenchao@163.com, Tel.: +86 15209227470
}

\begin{abstract}
Clinching technology is widely used to join sheet materials in manufacturing fields, especially in automotive lightweight applications. However, the clinched joints have a weak static strength and high protuberance, which influence the application of the clinching technology. In order to improve the static strength and decrease the protuberance height of clinched joint, a new method to join aluminum alloy sheet materials with two-strokes flattening clinching (TFC) was investigated in this paper. The tension-shear strength, cross-tension strength, energy absorption and failure modes of clinched joint and TFC joint were investigated. Furthermore, the stiffness and the hardening exponent of the joints under different experimental tests were studied. The results indicated that the mechanical behaviors of the joints were optimal when the forming force was $35 \mathrm{kN}$. The maximum cross-tension and tension-shear strength of TFC joint were increased by $514 \mathrm{~N}$ and $1145 \mathrm{~N}$ on average compared with the initial clinched joint. The main failure modes of the joints were the neck fracture mode under the tension-shearing and cross-tension test. In addition, the stiffness and hardening exponent explained the variation of the mechanical properties of the joints under different forming forces.
\end{abstract}

Key words: Two-strokes flattening clinching; Static strength analysis; Mechanical properties; Hardening exponent

\section{Introduction}

In recent years, aluminum alloys have been widely used in manufacturing fields due to their light weight and high hardness, especially in the automotive industry [1-3]. The joining method of these aluminum alloys has becomes a hot research topic. The methods of joining aluminum alloys in automobile manufacturing mainly include welding, resistance spot welding, riveting, adhesive bonding and clinching. Welding and resistance spot welding are both chemical joining methods. The joining process consumes a lot of energy and generates harmful gases. Furthermore, welding and resistance spot welding are not suitable for joining the 
different alloy sheet materials because of the different melting points. Different from welding, adhesive bonding and clinching can join the similar and dissimilar aluminum alloys using mechanical methods [4]. However, the quality of the adhesive bonded joints is severely affected by the temperature, and the process of the adhesive bonding is time consuming. The clinching process has the characteristics of short time-consuming and high economic efficiency. The clinched joints are more stable than adhesive bonding joints and are less affected by the temperature [5,6]. Clinching is the most economical way to join sheet materials. However, the strength of clinched joints is lower than that of spot welded joints. Many researchers have studied the clinching process to optimize the quality of clinched joints.

Clinching of similar and dissimilar sheet materials of titanium and aluminum alloys were investigated by $\mathrm{He}$ et al. [7]. Different combinations of titanium alloys and aluminum alloys as well as placement positions affected the strength of joint. The results showed that the mechanical properties of joints were better when the titanium alloy was taken as the lower sheet. Lambiase et al. [8] researched the clinched joints with different combinations of aluminum alloys and Glass Fiber Reinforced Polymer (GFRP) using different punches. They study results showed that the mechanical behaviors of joints are largely affected by the thickness of the metal/GFRP sheets. The clinching processes of dissimilar materials of aluminum alloy and Carbon Fiber Reinforced Plastic (CFRP) sheets were investigated by Lee et al. $[9,10]$. The authors optimized the parameters of the hole clinching tools to improve the performance of hole-clinched joints. They found that an important alignment factor affecting the static strength of clinched joints was the center difference between dies and the hole in lower sheet. Abe et al. [11,12] investigated the mechanical behavior of clinched joint using ultra-high-strength steel sheets. The results of their study found that the clinched joints had better fatigue strength than the resistance spot welded joints. Furthermore, the parameters of conventional clinching tools were optimized by He et al. [13]. Eshtayeh et al. [14] optimized the clinched joint using the Grey-based Taguchi method. The found that an increase in the thickness of the bottom or the neck thickness leads to a decrease in the interlock lock. Han et al. [15] investigated the effect of the bottom die parameters on the static strength of the joints. They found that the groove depth and die depth of the die have a significant impact on the quality of joints. Lambiase et al. [16] researched the effect of different dies on the static strength of clinched joints. The main results of the research found that static strength of the clinched joints created by the extensible dies are stiffer than that of the joints created by fixed dies. Mucha et al. [17] studied the influence of forming force and bottom thickness on static strength of the clinched joints. The authors found that the bottom thickness and static strength 
of clinched joints are negatively correlated within a certain range. It means that increasing the forming force within a certain range can improve the performance of the joint.

Moreover, the reshaping methods are also employed to enhance the quality of the clinched joints. Wen et al. [18] created a reshaping method using a matched pair of counter tools to increase the mechanical behaviors of the clinched joints. They found that the reshaping method can reduce the protuberance and enhance the strength of the joint. The average tension-shear strength of reshaped joints is enhanced by $17 \%$ versus to that of clinched joint. Chen et al. [19-21] studied height reducing methods to improve the quality of clinched joints. The protuberance of clinched joints can be reduced through the high reducing method with a pair of flat dies. The authors found that the reshaping force and the different combinations of material sheets affect the quality of the reshaped joints. However, as shown in Fig. 1, these methods cannot flatten the protuberances of the clinched joints.

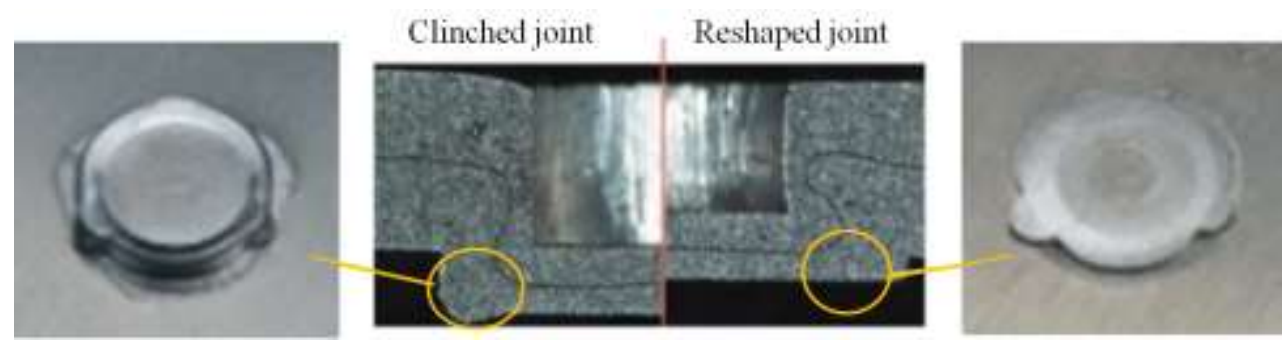

Fig. 1. The protuberances of clinched joint and reshaped joint [20]

In current study, a new clinching process is studied, which is able to improve the quality of joints and make the joints almost free of protuberance. The AA5052 sheet materials with the thickness of $2.0 \mathrm{~mm}$ were adopted in clinching process. The tension-shearing tests and cross-tension tests were conducted to evaluate the static strength of clinched joints. The effects of forming force and stroke on the joint strength, materials flow, failure mode, the stiffness, the hardening exponent and energy absorption were evaluated experimentally. Furthermore, in order to study the sheet material flow at different strokes, profiles of joints with different process parameters were studied comparatively.

The results showed that the TFC process can greatly improve the mechanical properties of initial joints. The quasi-static test showed that the tension-shear strength and cross-tension strength are increased by $78.2 \%$ and $45.2 \%$, respectively. Material flow analysis showed a $69.6 \%$ and $211.6 \%$ increase in neck thickness and interlock. Furthermore, the TFC joints exhibit a superior strength and absorb more energy during the cross-tension test.

\section{Two-strokes flattening clinching process}

Two-strokes flattening clinching (TFC) process was proposed to produce clinched joints 
with better mechanical behaviors, which is an optimization of conventional clinching process. As demonstrated in Fig. 2, the TFC process includes two strokes. The purpose of the first strokes is to form a mechanical clinched joint. The second stroke flattens the protuberance of the mechanical clinched joints. Clinching tools were used in TFC process, including blank holder, punch, double flap gaskets, bottom ring, flat die and anvil. The bottom ring was installed on the anvil with small fitting clearance. The double flap gaskets were obtained by cutting a complete ring, and the double flap gaskets were positioned under the bottom ring to ensure a certain cavity volume in the lower bottom dies.

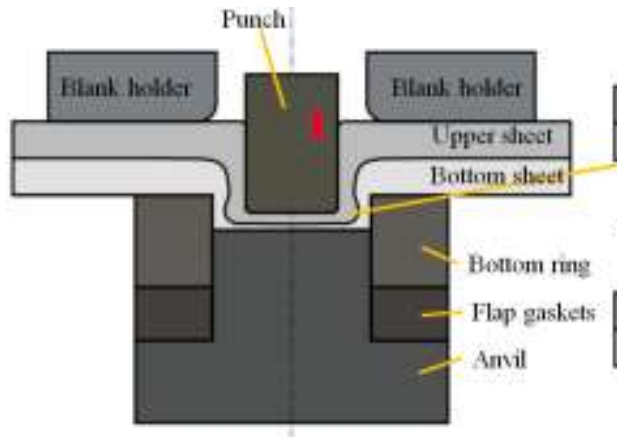

(a)

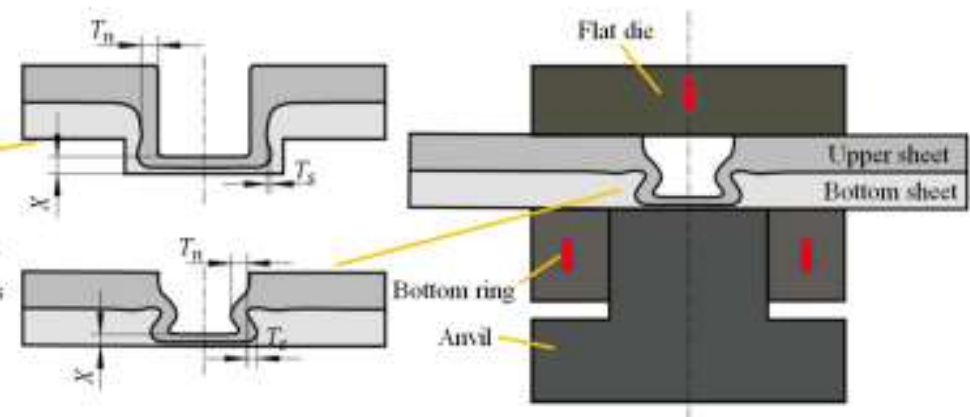

(b)

Fig. 2. The TFC process (a) the first stroke (b) the second stroke

As indicated in Fig. 2(a), the flap gaskets are installed on the anvil in the first stroke. The bottom ring is placed on the flap gaskets to ensure a certain depth of the bottom dies. The punch compresses the sheets. Initially, the sheets are subjected to forces within the elastic range, and sheets undergo elastic deformation. As the punch is gradually embedded in the upper sheet, the sheet materials are plastically deformed, and the material of the sheets gradually fills the cavity of the bottom dies to form the initial clinched joint. The important parameters of the initial clinched joint are mainly the interlock $\left(t_{s}\right)$, the neck thickness $\left(t_{n}\right)$ and the thickness of the bottom $(X)$. The bottom thickness $(X)$ of the initial clinched joint is controlled by the force at first stroke.

In the second stroke, the double flap gaskets are removed, leaving the room for the ring to move downward. The flat die is employed to press upper sheet of the initial clinched joint, forcing the bottom ring to move downward. The anvil acts upward on the protuberances of the initial clinched joint, making the materials of the protuberances to flow inward and gradually flatten the protuberances. The TFC joints are formed and automatically demolded. As shown in Fig. 2(b), the protuberance material of the joint flows to the hollow of the joint, so that the cross section of the TFC joint forms a funnel shape. The main parameters of the TFC joint also include the interlock $\left(t_{s}\right)$, the neck thickness $\left(t_{n}\right)$ and the bottom thickness $(X)$. In addition to 
these important parameters, the work hardening $(n)$ and stiffness $(K)$ of the joints are also significant parameters that affect the mechanical properties of the joints.

\section{Materials and methods}

\subsection{Materials}

AA5052 sheet materials are used in automobile bodies, and it has good ductility and strength. The TFC process was conducted on the AA5052 sheets materials with the thickness of $2.0 \mathrm{~mm}$. All sheets were obtained by cutting from the rolling direction. The size configuration of these sheets is thickness $2 \mathrm{~mm} \times$ length $80 \mathrm{~mm} \times$ width $25 \mathrm{~mm}$. The mechanical properties of AA5052 sheet materials were determined by uniaxial tensile tests with Instron 5982 universal tester. The experimental results were summarized in Table 1. Table 2 lists the chemical composition of AA5052 sheet materials.

Table 1

The principal mechanical properties of the AA5052 sheet materials

\begin{tabular}{clcc}
\hline $\begin{array}{c}\text { Mechanical } \\
\text { properties }\end{array}$ & Yield strength & $\begin{array}{c}\text { Young's modulus } \\
(\mathrm{MPa})\end{array}$ & $\begin{array}{c}\text { Poisson's } \\
(\mathrm{GPa})\end{array}$ \\
\hline AA5052 & 235.1 & 62.9 & ratio \\
\hline
\end{tabular}

Table 2

The chemical composition of AA5052 sheet materials

\begin{tabular}{llllllll}
\hline Chemical composition & $\mathrm{Cu}$ & $\mathrm{Mn}$ & $\mathrm{Si}$ & $\mathrm{Cr}$ & $\mathrm{Fe}$ & $\mathrm{Mg}$ & $\mathrm{Al}$ \\
\hline AA5052 Content $(\mathrm{w} / \%)$ & 0.015 & 0.056 & 0.116 & 0.190 & 0.371 & 2.362 & 96.889 \\
\hline
\end{tabular}

3.2 Forming procedure

The CMT-5105GJ machine was employed to exert the experiment. The clinching tools were connected to the GMT-5105GJ machine by a connecting rod. The blank holder, punch, double flap gaskets, bottom ring, flat die and anvil are the main components of TFC tools. The blank holder, double flap gaskets, bottom ring and anvil form the bottom dies. The bottom ring is sleeved on the anvil, and the double flap gaskets underneath determines its height. The geometric dimension of the bottom dies is described in Fig. 3. The diameter of the punch used in this experiment is $5.4 \mathrm{~mm}$. The descending rate of the punch and the maximum force were determined by the CMT-5105GJ machine. The different punch forces were configured to obtain different clinched joints. Different punch forces were set to $30 \mathrm{kN}, 35 \mathrm{kN}$ and $40 \mathrm{kN}$ in the first stroke, and the punch speed was set to a fixed valued of $2 \mathrm{~mm} / \mathrm{min}$. The control pattern 
of the punch was configured to 'controllable force'. In additional, the preload of the punch is set to $10 \mathrm{~N}$. In the second stroke, the double flap gaskets were removed. The upper sheet was stamped by a flat die. Similarly, the control pattern of CMT-5105GJ machine was configured to 'controllable force'. The force of the flat die was set to $35 \mathrm{kN}$, and the loading velocity was configured to a constant $4 \mathrm{~mm} / \mathrm{min}$.

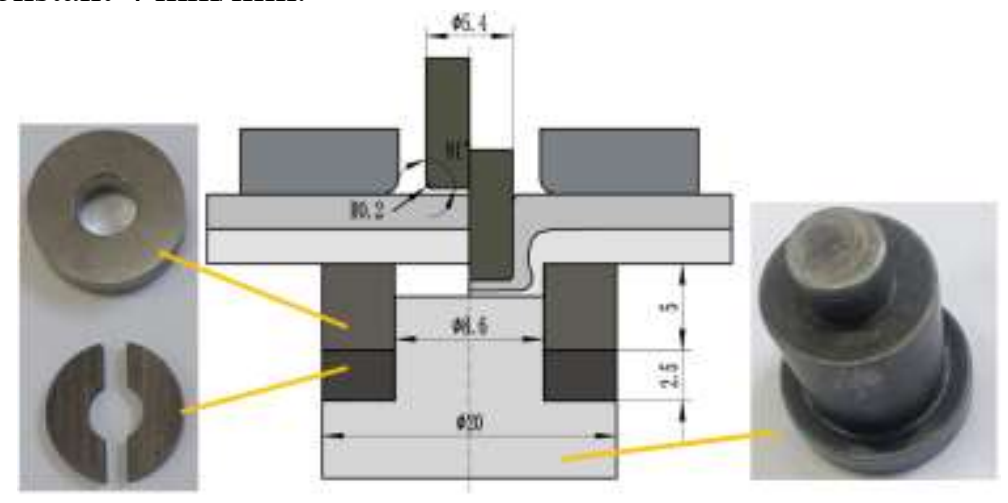

Fig. 3. The clinching tools of TFC process

\subsection{Static strength test}

Static strength testing is an effective way for evaluating the quality of clinched joints. In general, the static strength is evaluated by two methods, one is the cross-tension test, and the other is the tension-shearing test. The cross-tension strength and the tension-shear strength of the clinched joints are obtained from cross-tension and tension-shearing test, respectively. L'uboš et al. [22] and Mucha et al. [23] used the tension-shearing strength to evaluate the mechanical performances of clinched joints. Stephan et al. [24] evaluate the static strength of the clinched joint with cross-tension strength. In order to obtain the comprehensive mechanical performances of clinched joints, the tension-shearing and cross-tension tests are all performed on the clinched joints in this research. The joint specimen employed for cross-tension test is displayed in Fig. 4(a). Another joint specimen employed for tension-shearing test is depicted in Fig. 4(b). As shown in Fig. 5, different types of joint specimens are held by different clamping tools. Fig. 5(a) illustrates the clamping tools for tension-shearing test specimens, and Fig. 5(b) illustrates the clamping tools for cross-tension test specimens. The tension-shearing and cross-tension tests were performed by CMT-5105GJ universal testing machine. In the experimental test, the ascent speed of the CMT-5105GJ machine was constant at $4 \mathrm{~mm} / \mathrm{min}$. When the force and displacement curve on CMT-5105GJ tester suddenly drops, the joint fails completely, ending the test and recording the data. The static strength of each joint was obtained from the test results of three test specimens.

As shown in Fig. 6, button separation and neck fracture are the main failure modes during 
the static experimental test of the joints. The failure modes reflect the mechanism of action between the interlock and the neck thickness of the joint. Energy absorption is area enclosed by the force and displacement of joints before failure, which is an overall assessment of the mechanical properties of the clinched joints (see Fig. 7). Hardening exponent ( $n$ ) describes the work hardening characteristics of the sheet materials during clinching process (see Fig. 8). The hardening exponent $(n)$ can be obtained from fitting the displacement-load curves before the joint failure by the following formula:

$$
F=A\left(X_{0}+X\right)^{n}
$$

Where $F$ and $X$ are the load and the displacement of the joint, $A$ and $X_{0}$ are the coefficient and initial displacement, respectively. Coefficient $A$ mainly affects the amplitude of the curves, and $X_{0}$ is the offset of the initial position of the curves. The hardening exponent $(n)$, which affects the main variation of the curves, was mainly studied in this experiment. Furthermore, the stiffness of joint $(K)$ is analyzed, which is the ability of joints to resist deformation during the elastic phase (see Fig. 7).

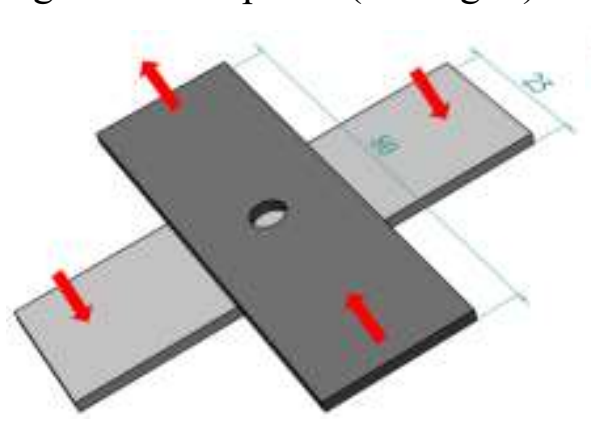

(a)

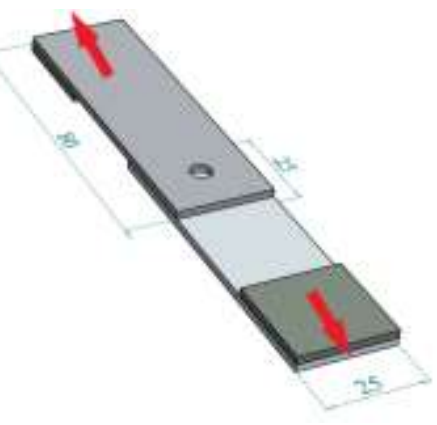

(b)

Fig. 4. Specimens: (a) specimen used in the cross-tension test and (b) specimen used in the tension-shearing test

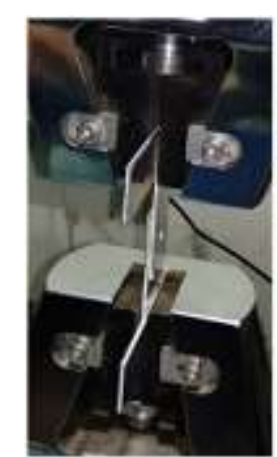

(a)

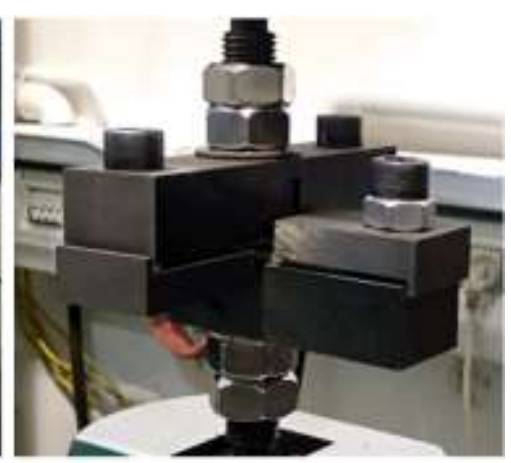

(b)

Fig. 5. Clamping tools: (a) clamps used in tension-shearing test and (b) clamps used in cross-tension test 


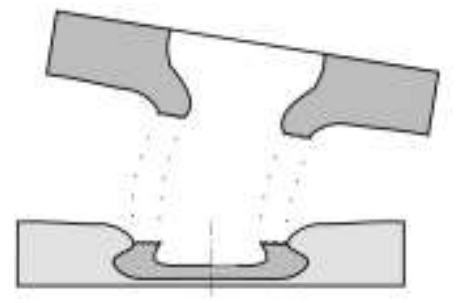

(a)

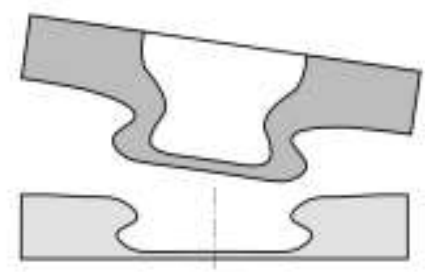

(b)

Fig. 6. Failure modes of joints (a) neck fracture (b) button separation

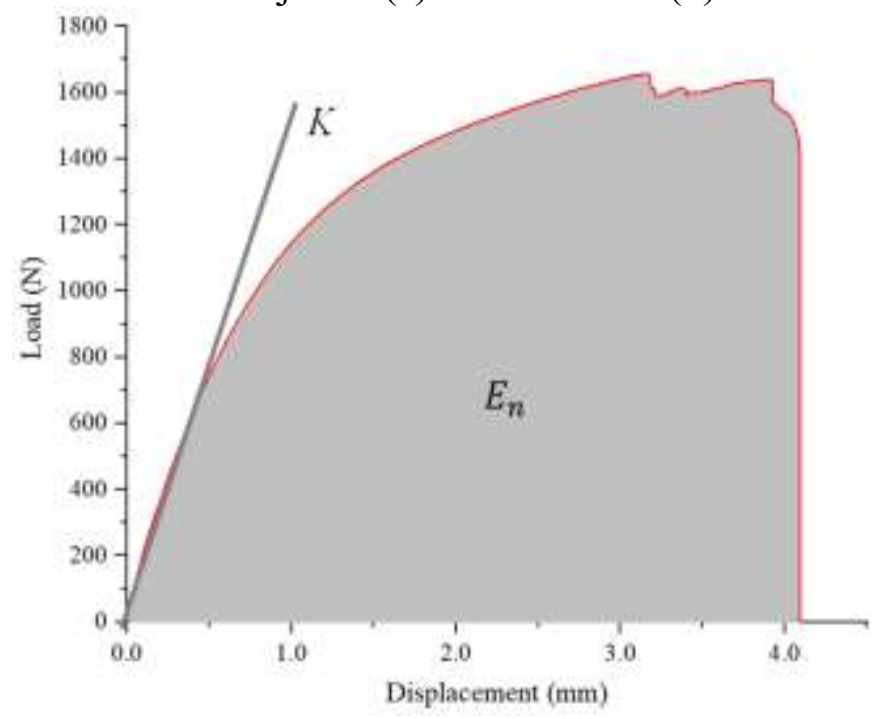

Fig. 7. The stiffness of joint

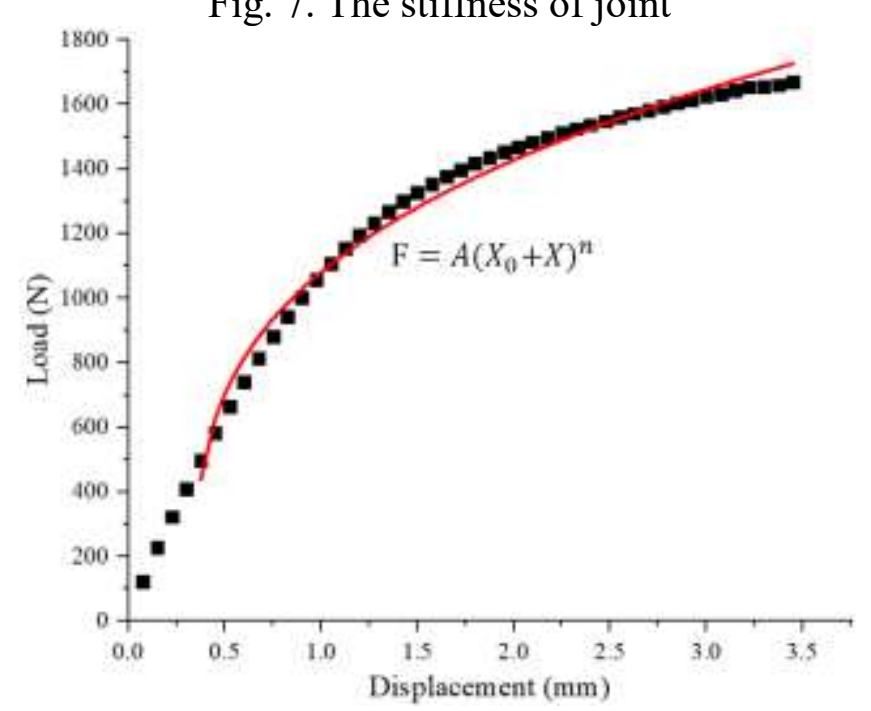

Fig. 8. The hardening exponent before the failure of the joint

\section{Static strength analysis and discussion}

\subsection{Cross-tension test}

The cross-tension strength of initial clinched joints and TFC joint with various forming forces were obtained from three cross-tension tests. The neck thickness and the interlock determine the static strength of the joint [25]. As presented in Fig. 9, the cross-tension strengths 
of TFC joints are all greater than that of initial clinched joint under various forming forces. Especial the increase extent is more significantly at forming force of $40 \mathrm{kN}$, which increasing extent reaches $39.3 \%$. The cross-tension strengths of initial clinched joints and TFC joints are highest when the force of the punch is $35 \mathrm{kN}$. Furthermore, the trend of strengths changes of both the initial clinched joints and TFC joints are increasing at first and then decrease with increasing forming force. The average strength of the initial clinched joint increases from 1103 $\mathrm{N}$ to $1681 \mathrm{~N}$ when the forming force changes from $30 \mathrm{kN}$ to $35 \mathrm{kN}$. Similarly, the average strength of the TFC joint increases from $1598 \mathrm{~N}$ to $1898 \mathrm{~N}$ when the forming force changes from $30 \mathrm{kN}$ to $35 \mathrm{kN}$. The protrusion materials of TFC joint flows into the neck of the joint, which increases the neck thicknesses of the joint as well as the size of the interlock. The joint is subjected to vertical upward tensile force in the cross tension test. The cross-tension strength of the joint is mainly determined by the neck thickness of the joint. Furthermore, as can be seen from Fig. 9 and Fig. 22, the two trends are basically the same, which further verifies the conclusion that the neck thickness is a determining factor for the static strength of the joint.

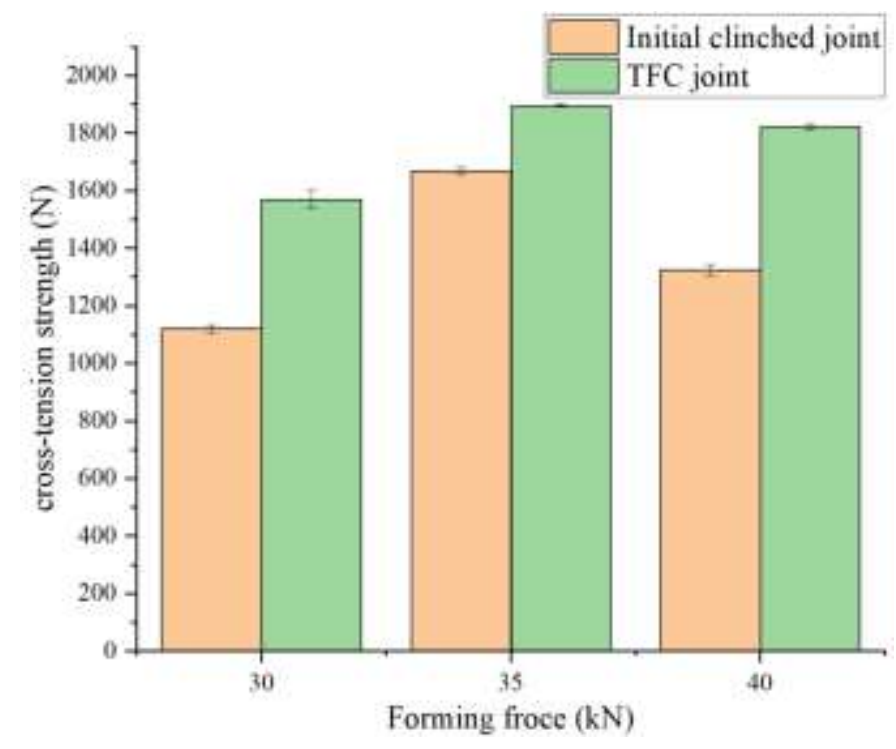

Fig. 9. The cross-tension strength of different joints

The force-displacement graphs of different joints under diverse punch forces are illustrated in Fig. 10. The straight lines of different colors represent the cross-tension load-curves of the initial clinched joints and TFC joints with various forming forces. A sudden drop in the force-displacement curves indicates failure of the joints. The TFC joint with different forming forces have larger deformation before the failure in the experimental tests. The stiffness $(K)$ and hardening exponent $(n)$ of the joint with various forces of the punch are shown in Fig. 11. The stiffness of the TFC joints is lower than that of initial clinched joints at 
different forming forces, which indicated that the deformation-resistant capacity of the TFC joint is lower than that of the initial clinched joint. The stiffness of the initial clinched joint is largest when the punch force is $35 \mathrm{kN}$. Similarly, the hardening exponent of the initial clinched joint is greater than that of TFC joint at different forming forces. The hardening exponent of the initial clinched joint reaches a minimum value of 0.29874 when the forming force is $35 \mathrm{kN}$.

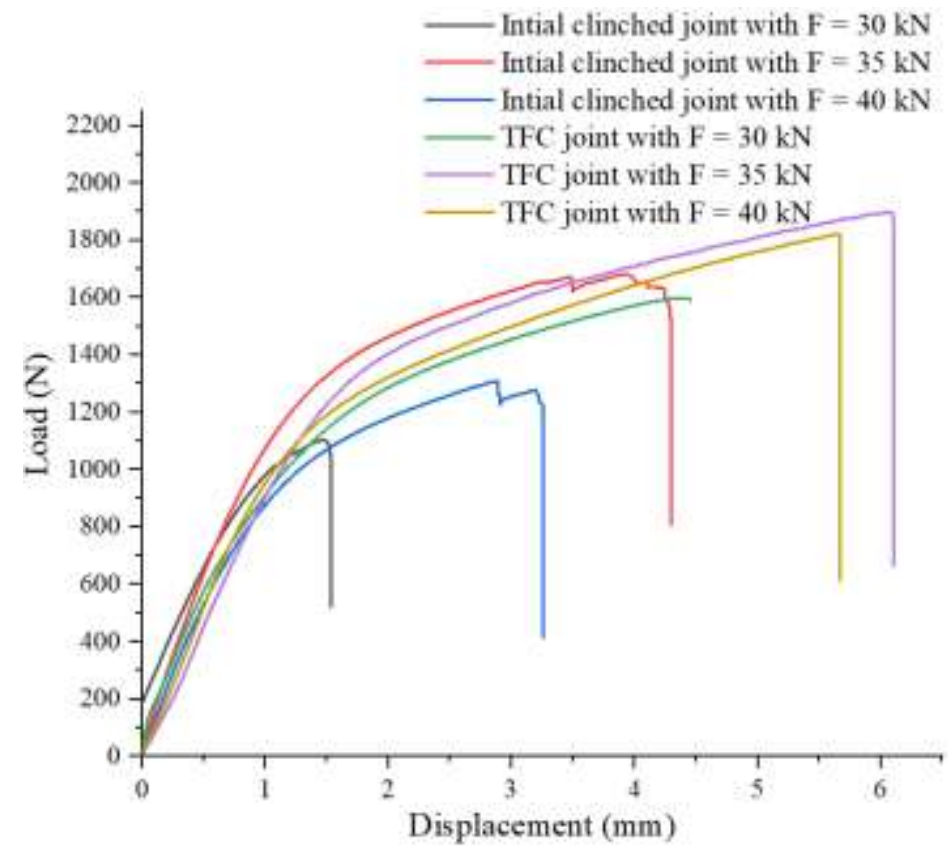

Fig. 10. The force-displacement curves of different joints under cross-tension test

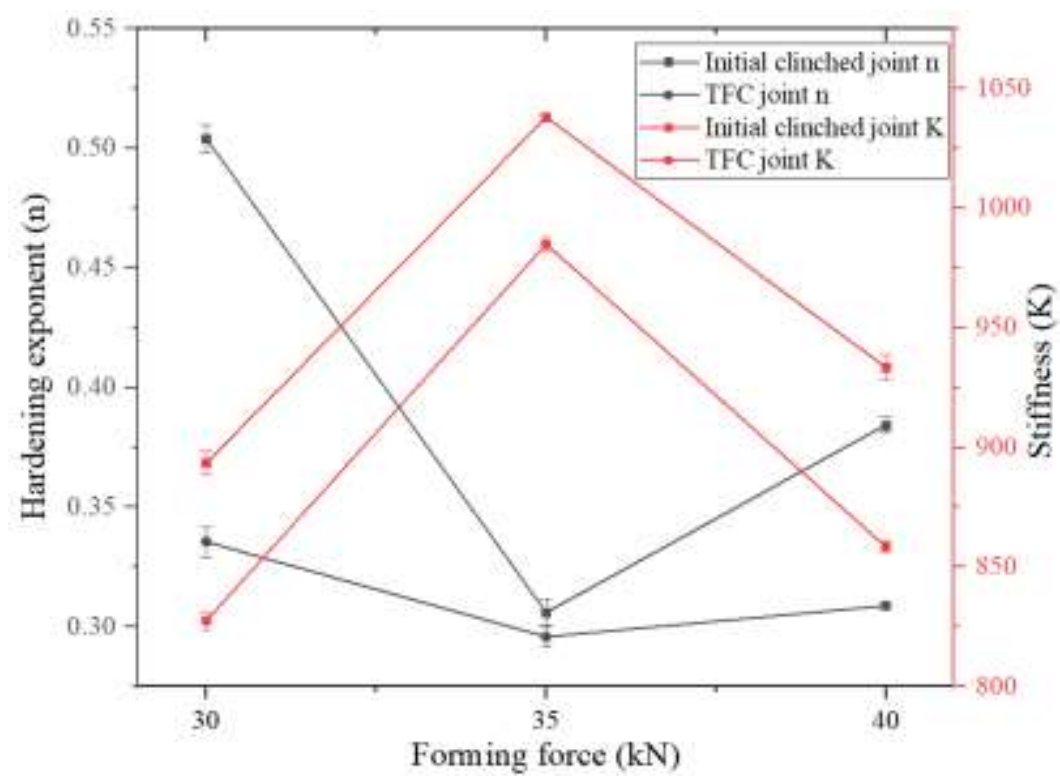

Fig. 11. The hardening exponent and stiffness of different joints

As shown in Fig. 12, button separation mode occurred in the cross-tension test of the initial clinched joint and TFC joint at the punch force of $30 \mathrm{kN}$. The main reason is that the 
forming force is small and the material flow of the upper sheet is insufficient, resulting in a small interlock. Another failure mode, neck fracture, is the primary failure mode of joints in the cross-tension test, which indicates that the thickness of the joint neck is the main factor that determines the strength of the joint.

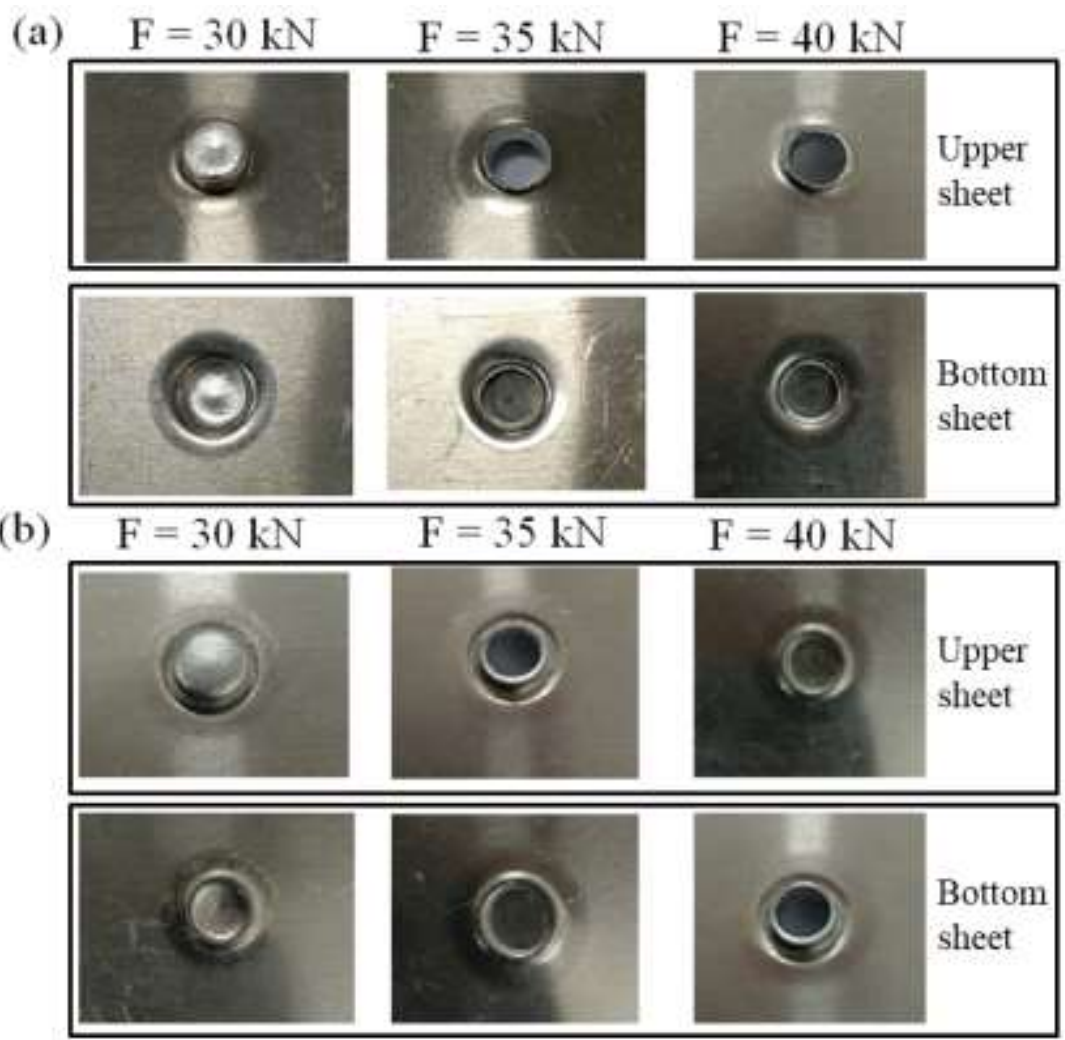

Fig. 12. Failure modes of joints in cross-tension test (a) initial clinched joint (b) TFC joint

\subsection{Tension shearing test}

The average of the three tension-shearing test results is used as the tension-shear strength of joint. The tension-shearing strength of the initial clinched joint is also the clinching joint under the forming force of the clinched joint. The tension-shearing strength is also determined by the neck thickness and interlock of the joint [26]. The tension-shear strength of the initial clinched joints and the TFC joints are shown in Fig. 13. The tension-shear strength of the TFC joint under different forming forces is greater than that of initial clinched joint. When the punch force is $35 \mathrm{kN}$, the tension-shear strengths of both TFC joints and initial clinched joints are maximum, with maximum values of $1801 \mathrm{~N}$ and $2946 \mathrm{~N}$, respectively. The maximum increase of the TFC joints compared to the initial joint is $1145 \mathrm{~N}$ at the punch force of $35 \mathrm{kN}$. Overall, the trend of tension-shear strength of both initial clinched joint and TFC joint increases at first and then decreases with increasing forming force. The maximum increase of the tension-shear strength of the initial joints is $211 \mathrm{~N}$ when the forming force changes from 30 
$\mathrm{kN}$ to $35 \mathrm{kN}$. Similarly, the maximum increase of tension-shear strength of TFC joint is $554 \mathrm{~N}$ when the forming force changes from $30 \mathrm{kN}$ to $35 \mathrm{kN}$. The joints are mainly subjected to lateral shear forces. The static strength of the joint is mainly influenced by the thickness of the neck. The tension-shear strength of initial clinched joint is basically same since the neck thickness of the joint is basically constant under different forming forces.

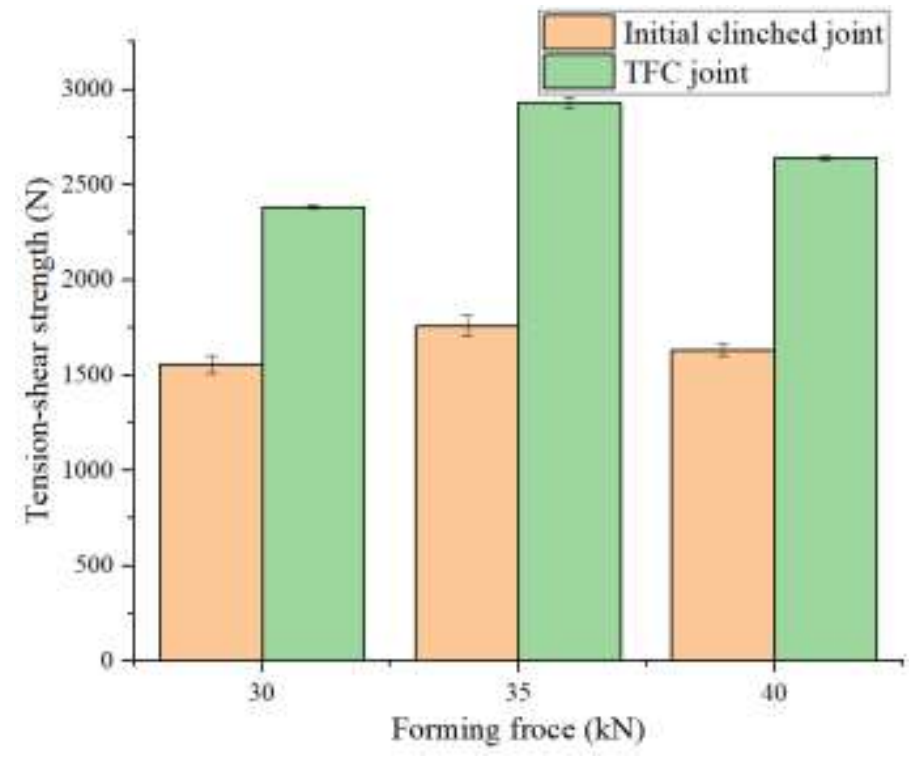

Fig. 13. The tension-shear strength of different joints

In order to study the changes in the mechanical performance of the joint under the tension-shearing test, the load-displacement curves of various joints are displayed in Fig. 14. The displacements of the TFC joints under different forming forces before failure are less than that of the initial clinched joints in the tension-shearing test. The stiffness and hardening exponent of different joint under different punch forces are depicted in Fig. 15. As the punch force increases, the stiffness of the joint increases at first and then decreases. The stiffness of both joints reaches maximum value, which means that the joints displacements are short before failure in the tension-shearing test. Conversely, the hardening exponent of both joints decreases at first and then increases as the forming force increases. The smaller the hardening exponent of the joint, the higher the strength at the same forming force.

From the Fig. 9 and Fig. 13, it can be observed that the tension-shear strength of the joints is higher than its cross-tension strength in the experimental test. The average tension-shearing strength of TFC joints is 1.54 times greater than its cross-tension strength. The average tension-shear strength of initial joints is 1.23 times greater than its cross-tension strength. Furthermore, the tension-shear strength of TFC joints is 1.55 times of its cross-tension strength when the forming force is $35 \mathrm{kN}$. This is mainly due to the combined effect of the cross-tension 
strength of the material being greater than its tension-shear strength and the transverse interference around the joint during the tension-shearing test.

The neck fracture mode is the primary fracture mode of joints in the tension-shearing test. As illustrated in Fig. 16, the tension-shear strength of joints is mainly determined by the thickness of the joint neck. The neck thickness of the TFC joint is greater than that of the initial clinched joint, which results in the higher tension-shear strength than that of initial clinched joint. Furthermore, the greatest force that the joints neck can be withstood, which can be equivalent to a ring subjected to shearing force [27,28]. As shown in Fig. 17, the maximum force $\left(F_{t}\right)$ can be calculated as follows:

$$
F_{t}=\sigma_{f} \cdot A_{N}=\pi \cdot\left(2 R_{p} t_{N}+t_{N} \cdot t_{N}\right) \cdot \sigma_{f}
$$

Where $\sigma_{f}$ is the fracture stress of joint neck. $A_{N}$, the area of the ring. $R_{p}$ and $t_{N}$ are the radius of the punch and the thickness of the neck, respectively.

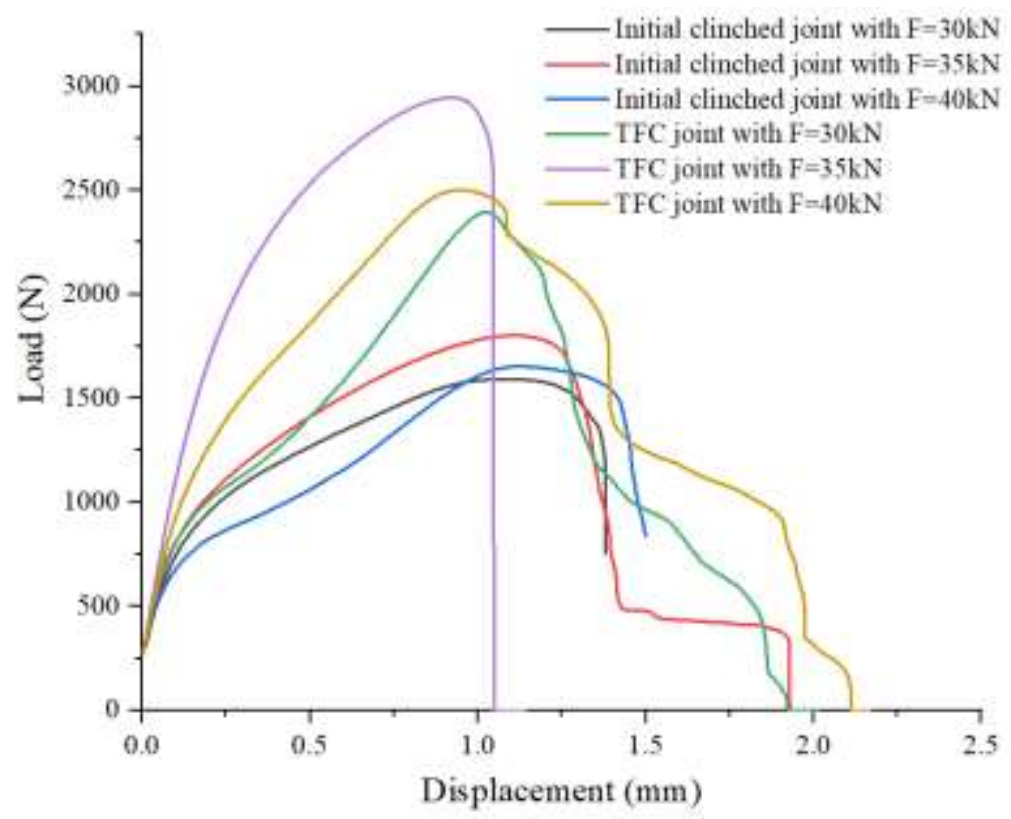

Fig. 14. The force-displacement curves of different joints under tension-shearing test 


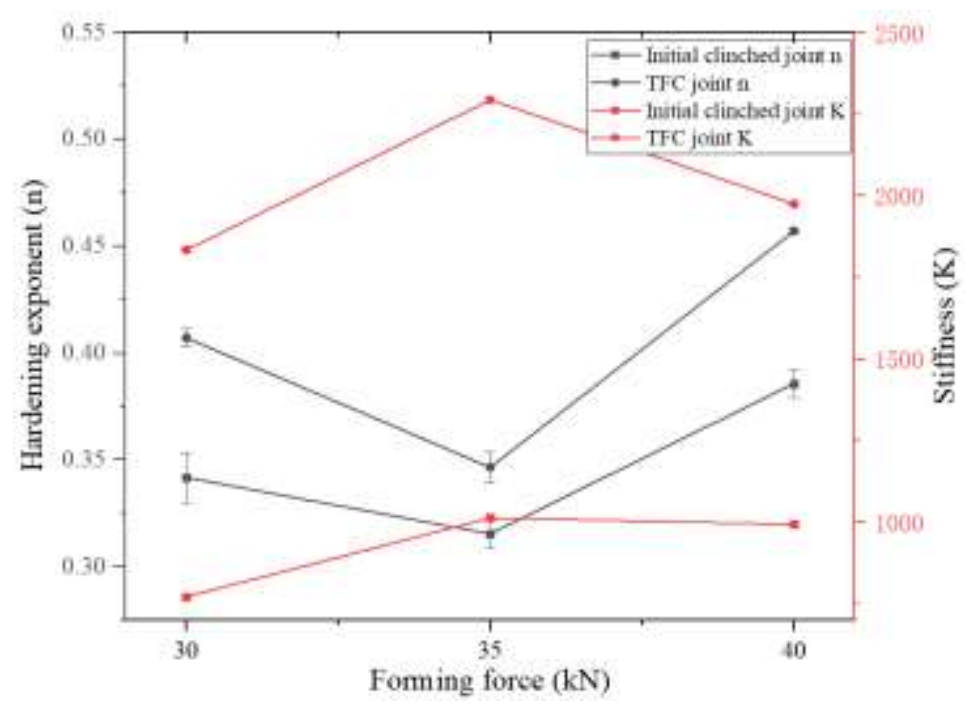

Fig. 15. The hardening exponent and stiffness of different joints

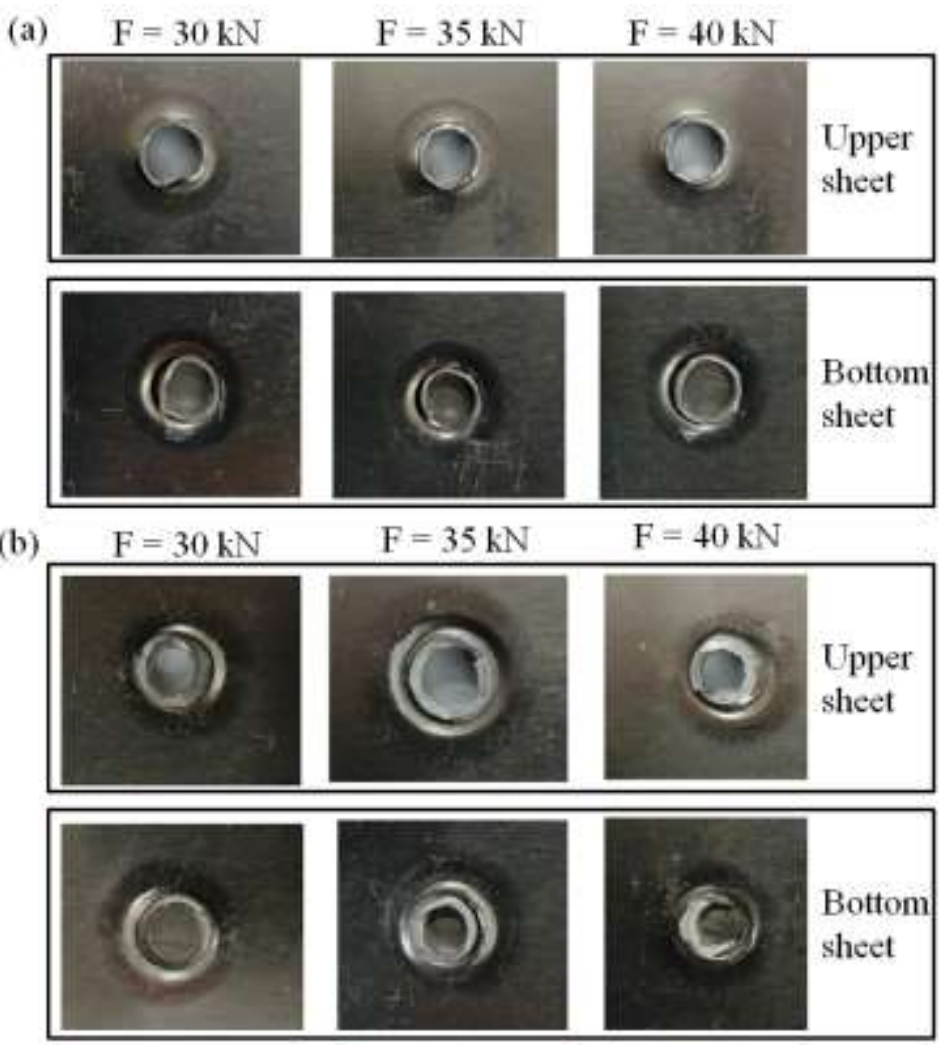

Fig. 16. Failure modes of joints in tension-shearing test (a) initial clinched joint (b) TFC joint

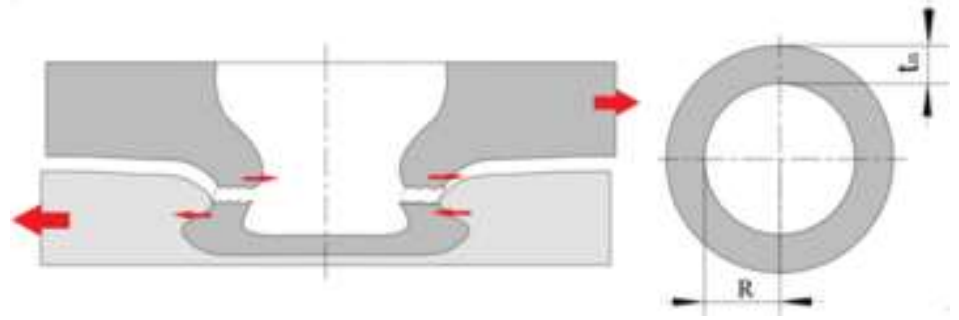

Fig. 17. Failure modes of joints 


\subsection{Energy absorption}

Impact resistance is one of the important factors for assessing structural stability, which is especially important in automobiles that are subjected to frequent shocks. Energy absorption is an significant indicator to evaluate the impact resistance [29]. More energy absorbed before joint failure, the better its impact resistance.

The value of energy absorption is obtained by gauging the area between the load-displacement curve and the abscissa in the coordinate system. As displayed in Fig. 18 and Fig. 19, the energy absorption of different types of joints has a large variation under different experiments. Overall, the energy absorption of TFC joints is greater than that of initial clinched joints. The value of energy absorption of the joints is not positively correlated with the forming force. In cross-tension experimental test, energy absorption of the initial clinched joints and TFC joints reaches maximum value at the punch force of $35 \mathrm{kN}$. The energy absorption of TFC joint increase $63 \%$ at most at the forming force from $30 \mathrm{kN}$ to $35 \mathrm{kN}$, and the maximum increase in the energy absorption of initial joints is $87.4 \%$ at the forming force from $30 \mathrm{kN}$ to $35 \mathrm{kN}$. Furthermore, the energy absorption of TFC joint is $142 \%$ at most than that of initial clinched joint at the forming force of $40 \mathrm{kN}$. In the tension-shearing experimental test, the strength of TFC joints is the greatest at the forming force of $35 \mathrm{kN}$, but its energy absorption is the smallest. The reason for this is that the stiffness of the TFC joint is greatest at the forming force of $35 \mathrm{kN}$, which means it can bear less deformation. The energy absorption of the TFC joint is largest when the punch force is $40 \mathrm{kN}$. The maximum increase in energy absorption of initial clinched joints and TFC joints are $24 \%$ and $38 \%$, respectively.

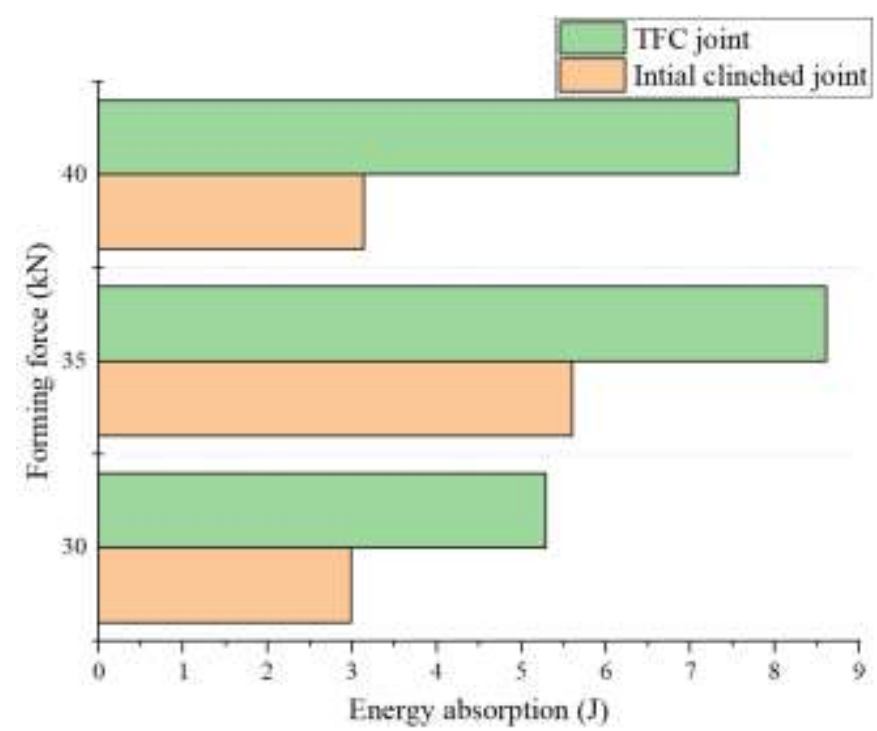

Fig. 18. The energy absorption of different joints under cross-tension test 


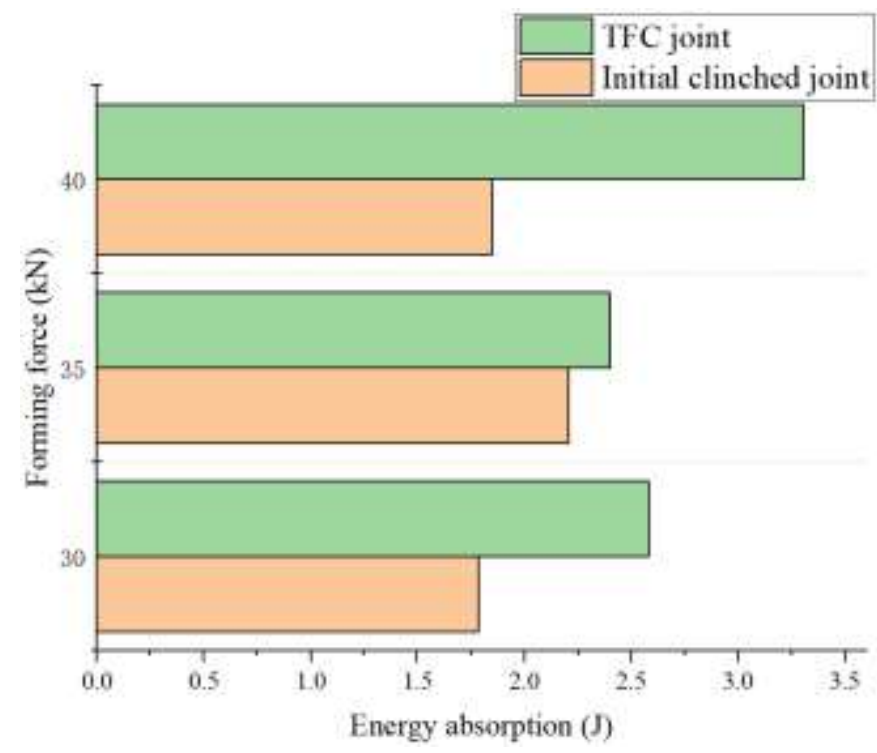

Fig. 19. The energy absorption of different joints under tension-shearing test

\subsection{Material flow}

The material flow of the sheet is affected by a variety of process parameters, among which the main influencing factors are the geometric parameters of the clinching tools and the punch force [30,31]. The important parameters of the joints (e.g. $\left.t_{n}, t_{s}, X\right)$ are determined by the material flow of sheets.

The cross-sections of the different joint at various forming force are displayed in Fig. 20. For the purpose of compare the material flow between initial clinched joint and TFC joint, two cross-sections with different process parameters are placed in the same figure. The cross-section of the initial clinched joint (IJ) is on left section of the subfigure, and the cross-section of the TFC joint (TFC) is shown on right section of the subfigure. The material flow of the TFC joint is better than that of initial clinched joint. The material of the protuberance of the joint flows upward, increasing the size of the interlock and the neck thickness, and reducing the size of the blind hole and the bottom thickness. The size of the interlock is negatively associated with the thickness of the joint neck.
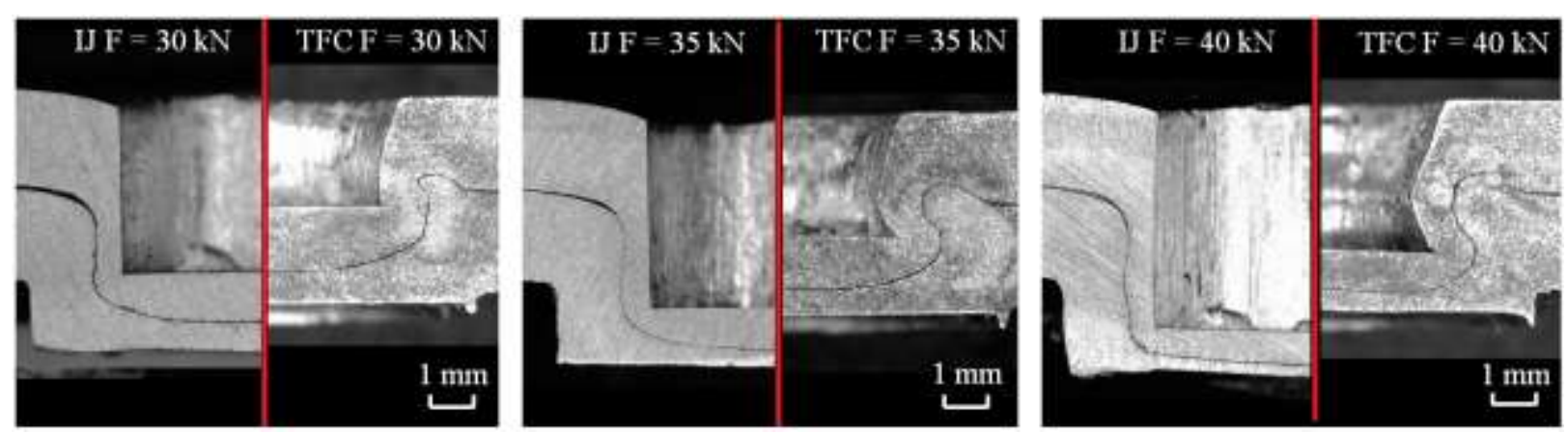

Fig. 20. The cross-sections of the different joints at different forming forces 
The bottom appearances of initial clinched joints and TFC joints at the forming force of $35 \mathrm{kN}$ are displayed in Fig. 21. The protuberance material of initial clinched joint flows to the neck of the joint through the TFC process and becomes almost flat. As can be seen from the Fig. 23, the bottom appearances of TFC joint become almost flat. The protrusion height is only $0.23 \mathrm{~mm}$ when the forming force is $35 \mathrm{kN}$.

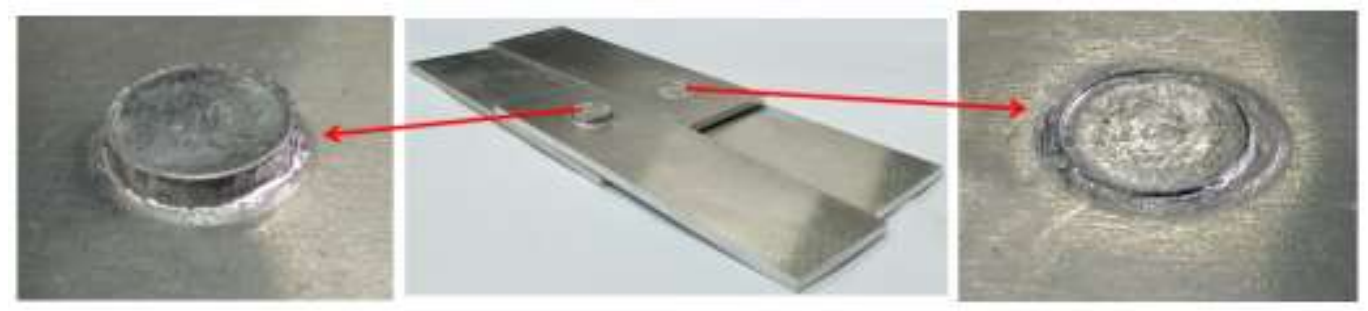

Fig. 21. The bottom appearances of initial clinched joint and TFC joint

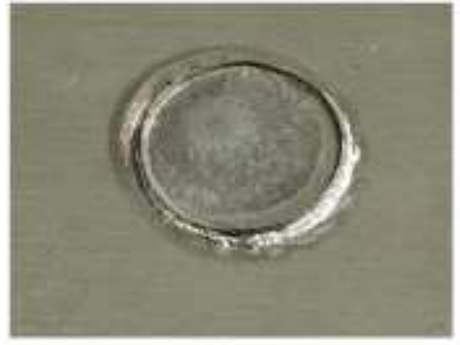

(a)

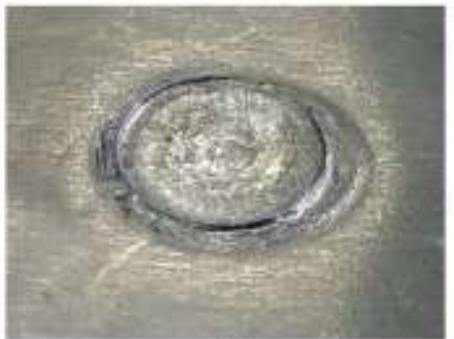

(b)

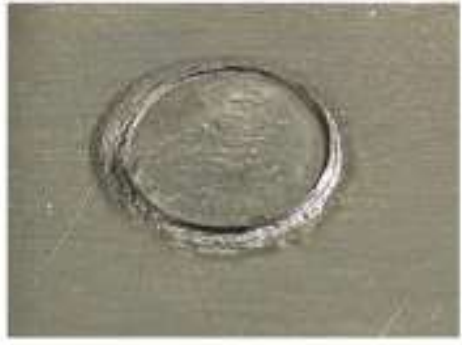

(c)

Fig. 22. The bottom appearances of the TFC joint under different forming forces (a) $30 \mathrm{kN}$ (b) $35 \mathrm{kN}(\mathrm{c}) 40 \mathrm{kN}$

4.5 Interlock and nick thickness

The value of interlock and the neck thickness of joint are negatively correlated. The mechanical performance of joints is mainly reliant on the thickness of neck and the size of interlock. The neck thicknesses and the interlocks of initial clinched joints and TFC joint with various forming forces are displayed in Fig. 23. The thicknesses and the interlocks of the joints are indicated by different colors (blank and red). The neck thickness and interlock of the TFC joint are significantly increased compared to initial clinched joint. When the force is $40 \mathrm{kN}$, the neck thickness and interlock of joint increase are the maximum, which are $69.6 \%$ and $211.6 \%$ respectively. Furthermore, the interlock value and the neck thickness of initial clinched joint and TFC joint are all reach the maximum at the punch force of $35 \mathrm{kN}$. The interlock of initial clinched joint is very small when the forming force is $30 \mathrm{kN}$, which is why the button separation occurs during the tension-shearing test. Overall, the protuberance of the joint is almost flattened by the anvil during the TFC process, which greatly improves the interlock and the neck thickness of joints. 


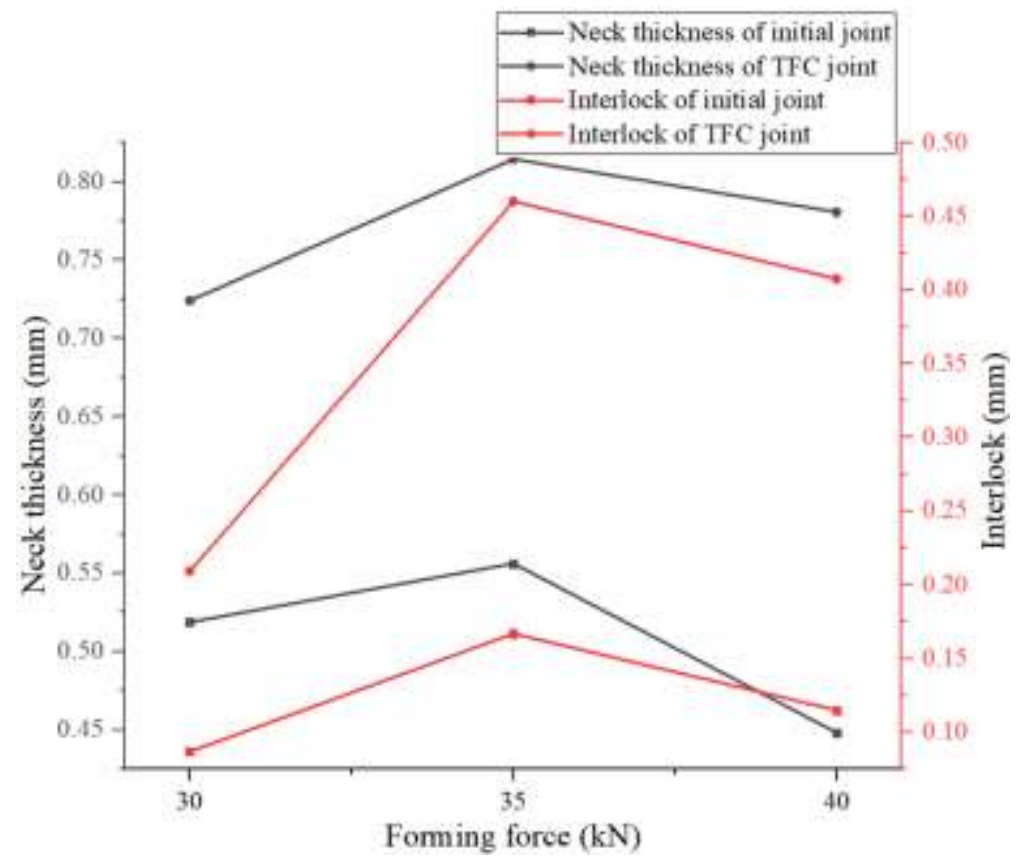

Fig. 23. The neck thickness and the interlock of different joints

\section{Conclusion}

Clinching aluminum alloy sheet materials with two-strokes flattening clinching method was investigated in present work, which can significantly improve the mechanical behavior of the joints. The AA5052 sheet materials were adopted in the experimental test. The materials of protuberance flow to the joint neck, which improves the neck thickness and interlock as well as flattens the initial clinched joint. The TFC process is effective for increasing the neck thickness and the interlock of the joint. The main findings of this work are as follows:

(1) The cross-tension strength and tension-shear strength of the joint can be enhanced by the TFC process. The cross-tension strength is significantly improved at the forming force of $40 \mathrm{kN}$, which increasing extent reaches 39.3\%. The maximum increase in tension-shear strength of the TFC joint compared to the initial clinched joint is $38.8 \%$.

(2) The stiffness of joint $(K)$ is the ability to resist deformation during the elastic deformation stage. The greater the stiffness value, the smaller the deformation of the joint under the same load. A joint with a hardening exponent of about 0.3 has good mechanical behaviors.

(3) All the failure mode of joints was neck fracture in the tension-shearing tests. The failure mode of button separation occurred in the cross-tension test of initial clinched joints when the punch force is $30 \mathrm{kN}$.

(4) All the TFC joints have better energy absorption comparing to initial clinched joints. The energy absorption of TFC joints is $142 \%$ at most than that of initial clinched joint joint at 
the forming force of $40 \mathrm{kN}$. Furthermore, the maximum increase in energy absorption of initial clinched joints and TFC joints are $24 \%$ and $38 \%$ at different forming forces, respectively.

(5) The TFC joints have better material flow than initial clinched joints. The protuberance material of initial clinched joint flows to the neck area through the TFC process and becomes almost flat.

\section{Funding}

This research work is supported by the National Natural Science Foundation of China (Grant No. 51805416), Young Elite Scientists Sponsorship Program by CAST, Natural Science Foundation of Hunan Province (Grant No. 2020JJ5716), the Project of State Key Laboratory of High Performance Complex Manufacturing, Central South University (Grant No. ZZYJKT2019-01), Huxiang High-Level Talent Gathering Project of HUNAN Province (Grant No. 2019RS1002), Hunan Provincial Natural Science Foundation for Excellent Young Scholars, and Fundamental Research Funds for the Central Universities of Central South University (Grant No. 2021zzts0651).

\section{Competing Interests}

The authors declare that they have no competing interest.

\section{Availability of data and materials}

The raw/processed data required to reproduce these findings cannot be shared at this time due to technical or time limitations

\section{Code availability}

Not applicable.

\section{Ethical Approval}

Not applicable.

\section{Consent to Participate}

Not applicable.

\section{Consent to Publish}

Not applicable.

\section{Authors Contributions}

Chao Chen conceived and designed the experiments; Hao Peng performed the experiments; 
Xiaoqiang Ren and Denglin Qin analyzed the data; Chao Chen and Xiangkun Ran contributed reagents/materials/analysis tools; Chao Chen and Hao Peng wrote the paper.

\section{References:}

1. Eshtayeh M, Hrairi M, Mohiuddin A (2016) Clinching process for joining dissimilar materials: state of the art. Int J Adv Manuf Technol 82 (1-4):179-195.

2. Shi C, Yi RX, Chen C, Peng H, Ran XK, Zhao SD (2020) Forming mechanism of the repairing process on clinched joint, Journal of Manufacturing Processes 50:329-335.

3. He XC (2010) Recent development in finite element analysis of clinched joints. Int J Adv Manuf Technol 48 (5-8):607-612.

4. Peng H, Chen C, Zhang HY, Ran XK (2020) Recent development of improved clinching process, Int J Adv Manuf Technol 110:3169-3199.

5. Chen C, Li YX, Zhang HY, Li YB, Pan Q, Han XL (2020) Investigation of a renovating process for failure clinched joint to join thin-walled structures, Thin Wall Struct 151:106686.

6. Chen C, Ran XK, Pan Q, Zhang HY, Yi RX, Han XL (2020) Research on the mechanical properties of repaired clinched joints with different forces, Thin Wall Struct 152:106752.

7. He XC, Zhang Y, Xing BY, Gu FS, Ball A (2015) Mechanical properties of extensible die clinched joints in titanium sheet materials. Materials \& Design 71:26-35.

8. Lambiase F, Durante M, Di Ilio A (2016) Fast joining of aluminum sheets with Glass Fiber Reinforced Polymer (GFRP) by mechanical clinching. J Mater Process Tech 236:241-251.

9. Lee C-J, Lee J-M, Ryu H-Y, Lee K-H, Kim B-M, Ko D-C (2014) Design of hole-clinching process for joining of dissimilar materials-A16061-T4 alloy with DP780 steel, hot-pressed 22MnB5 steel, and carbon fiber reinforced plastic. J Mater Process Tech 214 (10):2169-2178.

10. Lee C-J, Lee S-H, Lee J-M, Kim B-H, Kim B-M, Ko D-C (2014) Design of hole-clinching process for joining CFRP and aluminum alloy sheet. International journal of precision engineering and manufacturing 15 (6):1151-1157.

11. Abe Y, Saito T, Mori K-I, Kato T (2018) Mechanical clinching with dies for control of metal flow of ultra-high-strength steel and high-strength steel sheets. Proceedings of the Institution of Mechanical Engineers, Part B: Journal of Engineering Manufacture 232 (4):644-649.

12. Abe Y, Maeda T, Yoshioka D, Mori K-i (2020) Mechanical clinching and self-pierce riveting of thin three sheets of 5000 series aluminium alloy and $980 \mathrm{MPa}$ grade cold rolled ultra-high strength steel. Materials 13 (21):4741.

13. He XC, Liu FL, Xing BY, Yang HY, Wang YQ, Gu FS, Ball A (2014) Numerical and experimental investigations of extensible die clinching. Int J Adv Manuf Technol 74 (9-12):1229-1236.

14. Eshtayeh M, Hrairi M (2016) Multi objective optimization of clinching joints quality using Grey-based Taguchi method. Int J Adv Manuf Technol 87 (1-4):233-249.

15. Han SL, Wu YW, Gao Y, Zeng QL (2012) Study on clinching of magnesium alloy sheets with different lower die parameters based on DEFORM 2D. In: 2nd International Conference 
on Electronic \& Mechanical Engineering and Information Technology:1242-1245.

16. Lambiase F, Di Ilio A (2014) An experimental study on clinched joints realized with different dies. Thin Wall Struct 85:71-80.

17. Mucha J, Witkowski W (2014) The clinching joints strength analysis in the aspects of changes in the forming technology and load conditions. Thin Wall Struct 82:55-66.

18. Wen T, Wang H, Yang C, Liu LT (2014) On a reshaping method of clinched joints to reduce the protrusion height. Int J Adv Manuf Technol 71 (9-12):1709-1715.

19. Chen C, Zhao SD, Cui MC, Han XL, Ben NY (2017) Numerical and experimental investigations of the reshaped joints with and without a rivet. Int $\mathrm{J}$ Adv Manuf Technol 88 (5-8):2039-2051.

20. Chen C, Zhao SD, Han XL, Cui MC, Fan SQ (2016) Investigation of mechanical behavior of the reshaped joints realized with different reshaping forces. Thin Wall Struct 107:266-273.

21. Chen C, Zhao SD, Cui MC, Han XL, Fan SQ (2016) Mechanical properties of the two-steps clinched joint with a clinch-rivet. J Mater Process Tech 237:361-370.

22. Kaščák L', Spišák E, Mucha J (2013) Clinchrivet as an alternative method to resistance spot welding. acta mechanica et automatica 7 (2):79-82.

23. Mucha J, Kaščák Lu, Spišák E (2013) The experimental analysis of forming and strength of clinch riveting sheet metal joint made of different materials. Advances in Mechanical Engineering 5:848973.

24. Lüder S, Härtel S, Binotsch C, Awiszus B (2014) Influence of the moisture content on flat-clinch connection of wood materials and aluminium. J Mater Process Tech 214 (10):2069-2074.

25. Abe Y, Kato T, Mori K-i, Nishino S (2014) Mechanical clinching of ultra-high strength steel sheets and strength of joints. J Mater Process Tech 214 (10):2112-2118.

26. Gerstmann T, Awiszus B (2014) Recent developments in flat-clinching. Computational Materials Science 81:39-44.

27. He XC, Gao AF, Yang HY, Xing BY (2016) Mechanical behavior of clinched sheet material joints and strength design procedure. Acta Physica Polonica A 129 (4):698-700.

28. Lee C-J, Kim J-Y, Lee S-K, Ko D-C, Kim B-M (2010) Design of mechanical clinching tools for joining of aluminium alloy sheets. Materials \& Design 31 (4):1854-1861.

29. He XC, Zhao L, Yang HY, Xing BY, Wang YQ, Deng CJ, Gu FS, Ball A (2014) Investigations of strength and energy absorption of clinched joints. Computational Materials Science 94:58-65.

30. Lambiase F (2015) Clinch joining of heat-treatable aluminum AA6082-T6 alloy under warm conditions. J Mater Process Tech 225:421-432.

31. De Paula A, Aguilar M, Pertence A, Cetlin PR (2007) Finite element simulations of the clinch joining of metallic sheets. J Mater Process Tech 182 (1-3):352-357. 